Research Paper

\title{
COX-2/sEH dual inhibitor PTUPB suppresses glioblastoma growth by targeting epidermal growth factor receptor and hyaluronan mediated motility receptor
}

\author{
Junyang Li ${ }^{1, *}$, Yali Zhou ${ }^{1, *}$, Handong Wang ${ }^{1}$, Yongyue Gao ${ }^{1}$, Liwen Li $^{1}$, Sung Hee \\ Hwang ${ }^{2}$, Xiangjun $\mathrm{Ji}^{1}$ and Bruce D. Hammock ${ }^{2}$ \\ ${ }^{1}$ Department of Neurosurgery, Jinling Hospital, Medical school of Nanjing University, Nanjing, 210002, China \\ ${ }^{2}$ Department of Entomology and Nematology and UC Davis Comprehensive Cancer Center, University of California, Davis, CA \\ 95616, USA \\ *These authors are contributed equally to this work \\ Correspondence to: Handong Wang, email: njhdwang@hotmail.com \\ Bruce D. Hammock, email: bdhammock@ucdavis.edu \\ Keywords: cyclooxygenase-2, soluble epoxide hydrolase, epidermal growth factor receptor, hyaluronan mediated motility \\ receptor, glioblastoma \\ Received: June 10, 2017 \\ Accepted: August 26, 2017 \\ Published: September 15, 2017 \\ Copyright: Li et al. This is an open-access article distributed under the terms of the Creative Commons Attribution License 3.0 (CC BY 3.0), which \\ permits unrestricted use, distribution, and reproduction in any medium, provided the original author and source are credited.
}

\section{ABSTRACT}

Aims: Cyclooxygenase-2 (COX-2)/soluble epoxide hydrolase (SEH) dual inhibitor, PTUPB, has been demonstrated to inhibit angiogenesis, primary tumor growth and metastasis. The aim of this study is to investigate the effects of PTUPB on glioblastoma cells and xenograft model.

Results: We show here that PTUPB inhibits glioblastoma cell proliferation and G1 phase cell cycle arrest in vitro, and suppresses the tumor growth and angiogenesis in vivo. The expression and activation of epidermal growth factor receptor (EGFR) and its downstream kinases, ERK1/ 2 and AKT, are reduced by PTUPB, indicating that the EGF/ EGFR signaling pathway is a potential target. Moreover, PTUPB dramatically suppresses expression of hyaluronan mediated motility receptor (HMMR) in the glioblastoma cell lines and xenograft mouse model, suggesting that the HMMR is the other potential target.

Materials and Methods: Cellular immunofluorescence assays were used for cell staining of actin fibers and HMMR. CCK-8 kit was used for cell proliferation assay. Cellcycle analysis was performed by flow cytometry. Quantitative real-time PCR assay was performed to test mRNA level. Western blot analysis was used to test protein expression. Immunohistochemical staining assay was used for xenograft tumor tissue staining of Ki-67, CD31 and HMMR. The SPSS version 17.0 software was applied for statistical analysis.

Conclusions: Our data demonstrate that PTUPB is a potential therapeutic agent to treat glioblastomas.

\section{INTRODUCTION}

Glioblastomas are the most malignant central nervous system (CNS) tumors in adults. Despite the recent advances in therapeutic strategies including surgery, radiotherapy and chemotherapy, the prognosis of glioblastoma patients remains poor with a median survival of less than one year [1-3]. As solid tumors, glioblastomas are highly vascularized and lead to rapid cell proliferation [4]. Thus, therapies of anti-angiogenesis and anti-tumorigenesis should be concurrently considered for glioblastoma treatment. Although an earlier study demonstrated that bevacizumab plus radiotherapy and temozolomide do not improve survival in glioblastoma patients [1], a recent exploratory analysis suggested that the addition of bevacizumab to standard glioblastoma treatment may extend survival for patients who do not receive second-line therapy [5].

Thanks to recent advances in tumor-microenvironment, increasing evidence reveals the close connections between inflammation and cancers [6-8]. The cyclooxygenase-2 (COX-2) signaling pathway in the arachidonic acid (ARA) 
cascade plays key roles in both inflammation and cancer [9]. Besides the anti-inflammatory and analgesic effects, COX2 selective inhibitors (coxibs) also exert anti-tumorigenic effects on various cancers, including gliomas [10, 11]. Inhibition of COX-2 was shown to prevent tumor progression by blocking conversion of ARA to prostaglandin E2 (PGE2), a proinflammatory eicosanoid that promotes tumorigenesis and tumor-associated angiogenesis [12-14]. ARA can also be converted to epoxyeicosatrienoic acids (EETs) by cytochrome P450 (CYP) epoxygenases [15]. EETs are autocrine and paracrine lipid mediators that modulate ion transport and gene expression, and exert anti-inflammatory, analgesic, and cardioprotective effects. However, EETs are rapidly metabolized in vivo by soluble epoxide hydrolase (sEH) to dihydroxyeicosatrienoic acids (DHETs) which have no or less biological activity [16]. Therefore, sEH inhibitors (sEHIs) are used to stabilize endogenous EETs and thus preserve their biological activity [17]. Recently, Zhang, et al. [18] demonstrated that dual inhibition of COX-2 and $\mathrm{sEH}$ by a combination treatment synergistically suppresses lung tumor growth and metastasis. Then, COX-2/sEH dual inhibitors such as PTUPB were synthesized. Concurrent inhibition of both COX-2 and sEH using PTUPB as a single molecule dramatically suppresses angiogenesis and primary tumor growth and metastasis.

Given that the potential of PTUPB to suppress solid tumors by blocking angiogenesis, we investigated the effects of PTUPB on glioblastoma. In the present study, we demonstrated that PTUPB inhibits cell proliferation and G1 phase cell cycle arrest in glioblastoma cell lines, and suppresses both tumorigenesis and angiogenesis in glioblastoma xenografts. Moreover, we showed that PTUPB may exert anti-glioblastoma effects by suppressing expression of hyaluronan mediated motility receptor (HMMR) and by targeting epidermal growth factor receptor (EGFR) signaling pathway. Our data suggest that PTUPB may exert both anti-angiogenic and antitumorigenic effects on glioblastoma.

\section{RESULTS}

\section{PTUPB suppresses glioblastoma growth in vitro}

To investigate the effects of PTUPB on glioblastoma growth in vitro, U87 and U251 cells were treated with either DMSO (vehicle control) or PTUPB in various concentrations $(10,20,25$ or $30 \mu \mathrm{M})$ for 72 h. A cell counting kit- 8 (CCK-8) was used to test the cell proliferation. PTUPB inhibited cell proliferation in a concentration-dependent manner (Figure 1A). By performing immunofluorescence staining with FITCphalloidin, we found that $30 \mu \mathrm{M}$ PTUPB causes disruption of actin stress fibers and retraction of the cytoplasm, which results in change in cell morphology and loss of adhesion to the substratum (Figure 1B). These observations indicate that PTUPB may exert a cytochalasin-like effect characterized by disruption of actin cytoskeleton, leading to growth inhibition and cytotoxicity.

Then, we performed cell cycle analysis and found that $20 \mu \mathrm{M}$ PTUPB with $48 \mathrm{~h}$ treatment significant increases the percentage of G1 phase cells and conversely decreases the percentage of $\mathrm{S}$ and G2 phase cells (Figure 2A). Western blot also showed that PTUPB affects various cell cycle regulators for $\mathrm{G} 1$ to $\mathrm{S}$ phase transition. The expression of cell cycle promoters, CDK2, CDK4, CDK6, Cyclin D1, Cyclin D3 and c-Myc, were decreased, and the expression of cell cycle progression inhibitors, $\mathrm{p} 27^{\mathrm{Kip} 1}$ and $\mathrm{p} 21^{\mathrm{Waf} 1 / \mathrm{Cip} 1}$, were increased (Figure 2B).

\section{PTUPB reduces both expression and phosphorylation of EGFR}

EGFR signaling plays key roles in cytoskeletal and cell cycle regulation, and cell growth promotion [19-21]. Thus, we investigated whether PTUPB exerts the inhibitory effects by targeting EGFR signaling pathway. Recombinant human epidermal growth factor (hEGF) was used as an EGFR activator. $30 \mu \mathrm{M}$ PTUPB with either $24 \mathrm{~h}$ or $48 \mathrm{~h}$ treatment reduced the expression of EGFR protein (Figure 3A). Either 20 or $30 \mu \mathrm{M}$ PTUPB with $48 \mathrm{~h}$ treatment could deplete phosphorylation of EGFR at both Tyr1068 (p-EGFR ${ }^{\text {Tyr1068) }}$ and Tyr1173 (p-EGFR ${ }^{\text {Tyr1173 }}$ ) (Figure 3B). We also found that PTUPB depletes p-EGFR ${ }^{\text {Tyr1068 }}$ in the early phase $(1 \mathrm{~h}$ treatment $)$ but p-EGFR ${ }^{\text {Tyrl173 }}$ in the late phase $(6 \mathrm{~h})$ (Figure $\left.3 \mathrm{C}\right)$. The expression of GRB2, an adaptor protein that directly binds to $\mathrm{p}$-EGFR ${ }^{\mathrm{Ty} 1068}$ and regulates EGFR/MAPK signaling, was also reduced, and the expression and phosphorylation of ERK1/2 and AKT were suppressed by PTUPB (Figure 3D).

\section{PTUPB suppresses the expression of HMMR and stemness markers and regulators}

After treating both U251 and U87 cells with either DMSO (vehicle control) or PTUPB, the expression of HMMR mRNA level was determined by quantitative real time-PCR assay (Figure 4A) and HMMR protein was tested by western blot and cellular immunofluorescence (Figures $4 \mathrm{~B}$ and $4 \mathrm{C}$ ). Both protein and mRNA level of HMMR is remarkably suppressed by PTUPB in a concentration dependent manner.

Targeting HMMR has been demonstrated to inhibit the expression of stemness markers and regulators and the activation of ERK1/2 [22]. We tested the expression of BMI1, SOX2 and ERK1/2 in PTUPB treated U251 and U87 cells, and found that PTUPB significantly inhibits the expression of BMI1, SOX2 and the activation of ERK1/2 (Figures 4D). ZEB1 is a target of SOX2 and has been shown to be co-expressed with SOX2 in glioblastoma [23]. We then tested the expression of ZEB1 in PTUPB treated U251 and U87 cells, and found that PTUPB also inhibits expression of ZEB1 (Figures 4D). 


\section{PTUPB suppresses glioblastoma growth in vivo}

To investigate the effects of PTUPB on glioblastoma in vivo, we built a subcutaneous glioblastoma xenograft model in BALB/c nude mice. As shown in Figure $5 \mathrm{~A}$ and $5 \mathrm{~B}$, PTUPB significantly suppressed tumor growth. Then, we dissected the xenograft tumors for immunohistochemical staining. As seen in Figure 5C, PTUPB lowered expression of Ki-67, CD31 and HMMR. $\mathrm{Ki}-67$ is a key biomarker of cancer cell proliferation and HMMR plays key roles in maintaining tumor growth and malignance. Lower CD31 expression in PTUPB-treated tumors represents the inhibition of tumor angiogenesis. Thus, our data indicated that PTUPB inhibits glioblastoma growth in vivo.

\section{DISCUSSION}

COX-2 is activated in many cancers and contributes to poor prognosis of malignances by enhancing resistance to chemotherapy and/or radiotherapy [24-26]. Therefore, targeting COX-2 has been demonstrated to be effective in treating cancers, including malignant gliomas [10]. Meanwhile sEH inhibitors have been demonstrated to reduce cardiovascular side effects of coxibs [27] and gastrointestinal erosion associated with COX inhibition [28]. sEHIs also potentiate anti-inflammatory and antiangiogenic effects of coxibs [18, 29-31]. Dual inhibition of COX-2 and SEH by either a combination of selective inhibitors of each enzyme or a COX-2/sEH dual inhibitor PTUPB as a single agent suppress primary tumor growth and metastasis by inhibiting tumor angiogenesis with the mechanisms of reduction of VEGF and PGE2, stabilization of EETs and inhibition of endothelial cell proliferation [18].

In the present study, the effects of PTUPB on human glioblastoma cells and the xenograft model were tested. We found that $20 \mu \mathrm{M}$ PTUPB significantly inhibits cell proliferation and induces G1 phase cell cycle arrest in multiple glioblastoma cell lines. Then, we performed immunofluorescence staining of actin stress fibers with FITC-phalloidin to present the morphology of cells treated. $30 \mu \mathrm{M}$ PTUPB significantly disrupts cellular actin
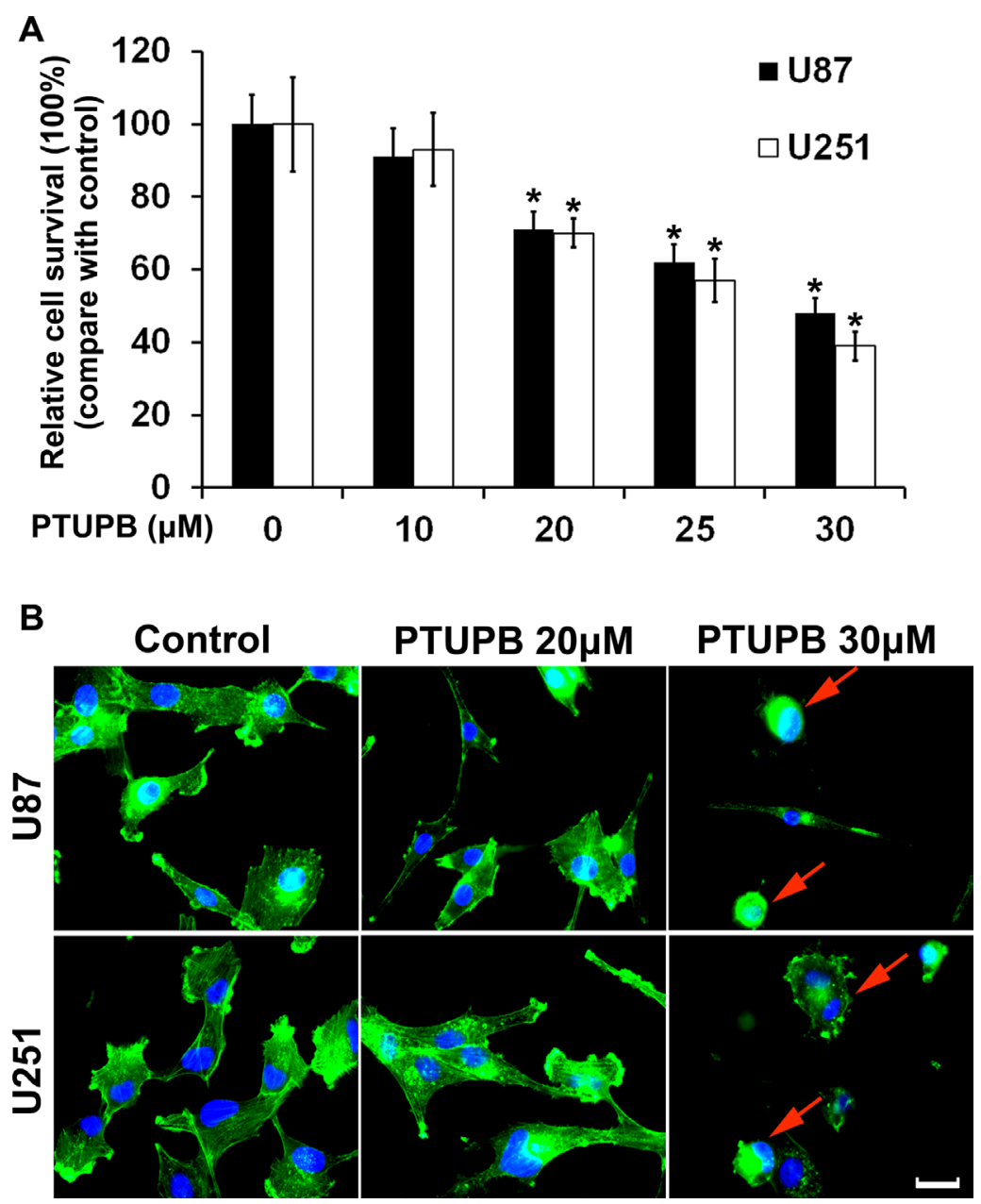

Figure 1: PTUPB inhibits cell proliferation and disrupts actin stress fibers. (A) PTUPB inhibits human glioblastoma U87 and U251 cell proliferation in a concentration-dependent manner starting from $20 \mu \mathrm{M}$ concentration $\left({ }^{*} P<0.05\right.$, compare with the control group). (B) $30 \mu \mathrm{M}$ PTUPB induces disruption of actin stress fibers and retraction of the cytoplasm in U251 and U87 cells. The actin stress fibers are shown in green and the nuclei are shown in blue. The red arrows point cell morphology change and cytoplasm retraction. Scale bar $=10 \mu \mathrm{m}$. 
cytoskeleton and induces retraction of the cytoplasm and loss of cell adhesion to the substratum, suggesting that PTUPB possesses cytochalasin-like anti-actin effect that leads to cell growth inhibition and following cell death [32]. Although $20 \mu \mathrm{M}$ PTUPB inhibits cell proliferation, it does not disrupt actin cytoskeleton, indicating that PTUPB may induce more dramatic cell growth inhibition by disrupting the actin and inducing loss of cell adhesion.

Next, we studied whether PTUPB affects EGFR, a critical receptor tyrosine kinase that promotes glioblastoma angiogenesis and increases glioblastoma cell proliferation, migration and invasion [33-37]. EGFR is overexpressed in $50-60 \%$ of glioblastomas and is
A

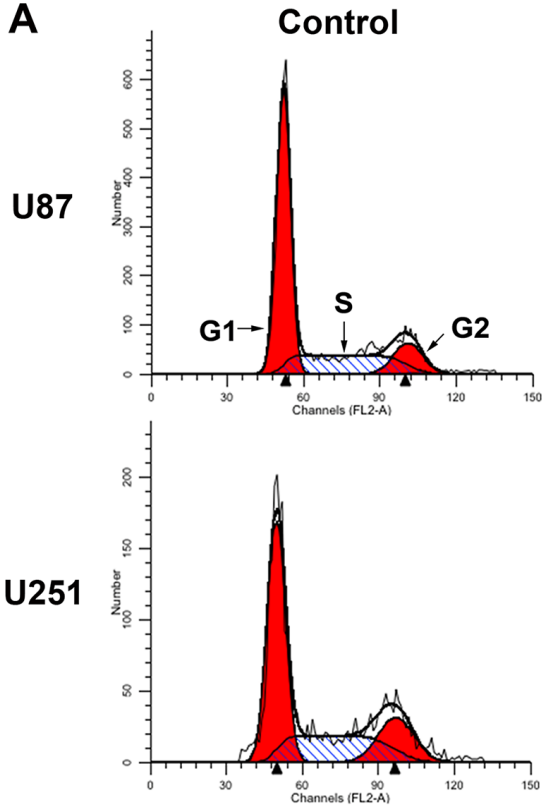

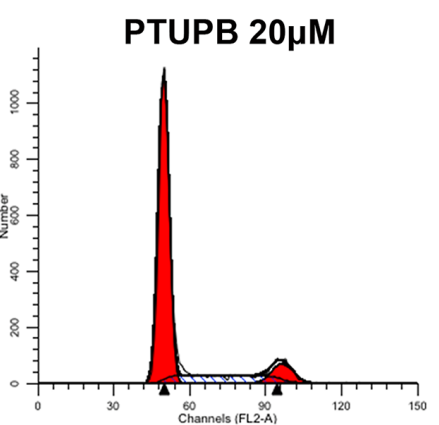
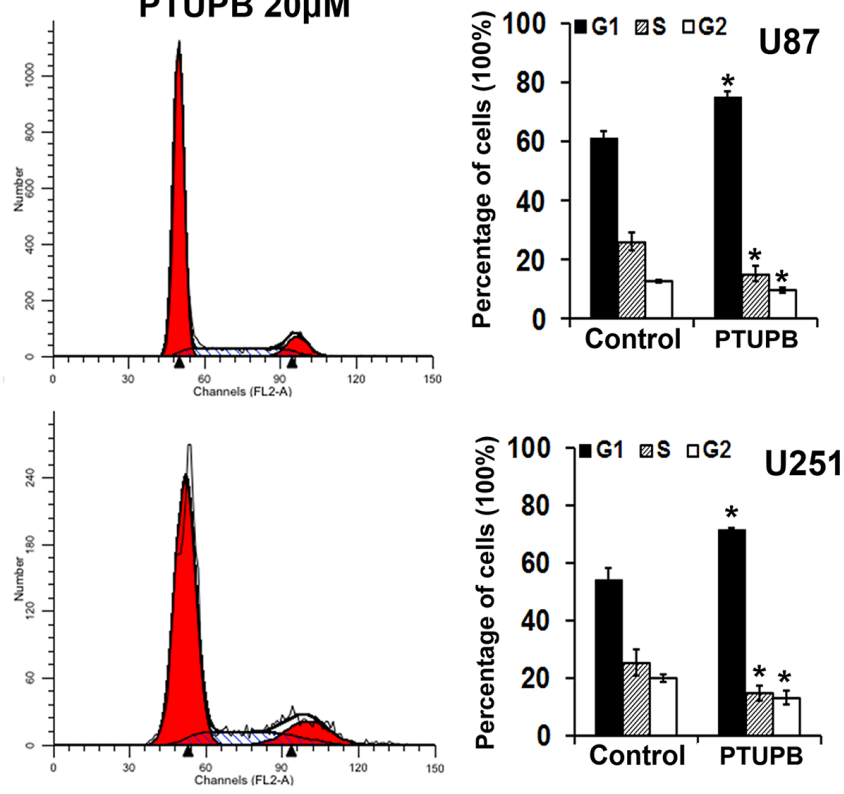

B
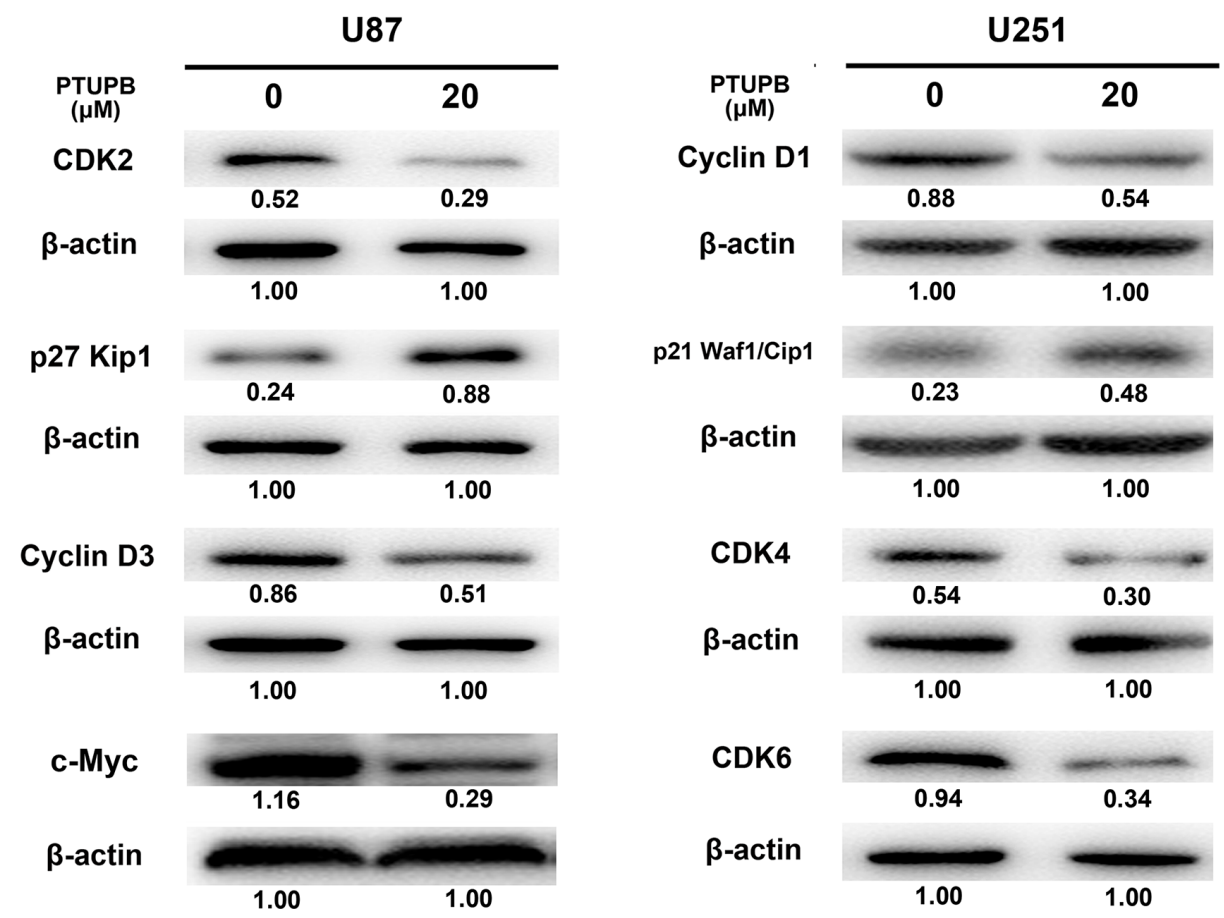

Figure 2: The effect of PTUPB on cell cycle. (A) $20 \mu \mathrm{M}$ PTUPB (48-h treatment) increases the percentage of G1 phase cells and decrease the percentage of S and G2 phase cells, compared with the control $\left({ }^{*} P<0.05\right)$. (B) $20 \mu \mathrm{M}$ PTUPB (48-h treatment) reduces the expression of cell cycle promoters CDK2, CDK4, CDK6, Cyclin D1, Cyclin D3 and c-Myc and, increases the expression of cell cycle progression inhibitors, $\mathrm{p} 27^{\mathrm{Kip} 1}$ and $\mathrm{p} 21^{\text {Wafl/Cipl }}$. $\beta$-actin served as loading control. The immunoblotting bands were quantified by ImageJ and represented by relative values compare with loading control (1.00). 
amplified in $40 \%$ of the tumors, and half of these contain various EGFR mutations [34, 36]. Several tyrosine kinase inhibitors (TKIs) that target the EGFR have been evaluated in clinical trials for glioblastoma patients, but all have failed to meet expectations $[34,38]$. In the present study, we demonstrated that PTUPB depletes activated EGFR (p-EGFR ${ }^{\text {Tyr1068 }}$ and p-EGFR ${ }^{\text {Tyr1173) }}$ ) and reduces protein levels of EGFR and the expression and activation of its downstream kinases ERK1/2 and AKT. In the U251 and U87 glioblastoma cell lines, p-EGFR ${ }^{\text {Tyr1068 }}$ is spontaneously expressed, while EGF-induced p-EGFR ${ }^{\text {Tyr1173 }}$ is persistent (no less than $48 \mathrm{~h}$ ). The high levels of p-EGFR ${ }^{\text {Tyr1068 }}$ and p-EGFR ${ }^{\text {Tyr1173 }}$ represent the hyper-activity of EGFR signaling, but it is dramatically inhibited by PTUPB. Binding of GRB2 to the p-EGFR ${ }^{\text {Tyr1068 }}$ is crucial to the EGFR-induced MAPK signaling pathway [39]. Our data show that PTUPB also depletes GRB2 expression. We also found that $20 \mu \mathrm{M}$ PTUPB dramatically depletes p-EGFR, although it does not reduce the EGFR protein level. This result may partially support the G1 phase arrest induced by $20 \mu \mathrm{M}$ PTUPB. Unlike the ATP-competitive TKIs, PTUPB treatment does not deplete EGF-induced phosphorylation of EGFR (p-EGFR ${ }^{\text {Tyr1173}) ~ u n t i l ~} 6 \mathrm{~h}$ post dose, while Gefitinib, a widely-used EGFR TKI, inhibits EGF-induced p-EGFR in early phase (30 min) in glioblastoma cells [37]. Thus, we hypothesize that PTUPB may exert anti-EGFR effects by depleting phosphorylated-EGFR rather than blocking EGFR phosphorylation in an ATP-competitive mechanism. This different mechanism of action by PTUPB targeting EGFR may offer a supplementary strategy to avoid TKI-resistance. Nonetheless, how PTUPB affects the protein structure of EGFR remain unclear, and further studies are needed to unveil the mechanisms.

Then, we found that in both glioblastoma cells and xenografts PTUPB suppresses expression of HMMR, a multifunctional oncogenic protein which is highly expressed in malignant tumors [40-44]. HMMR not only regulates tumor cell proliferation and invasion, but

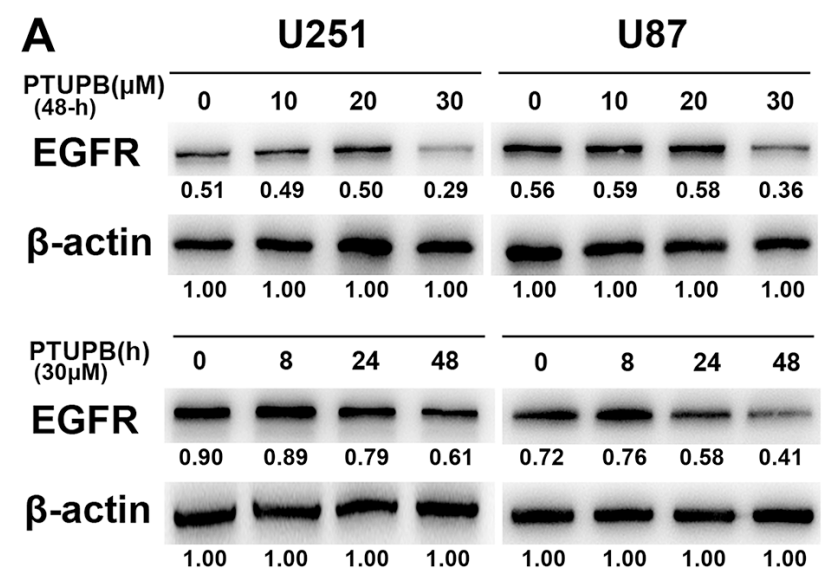

C

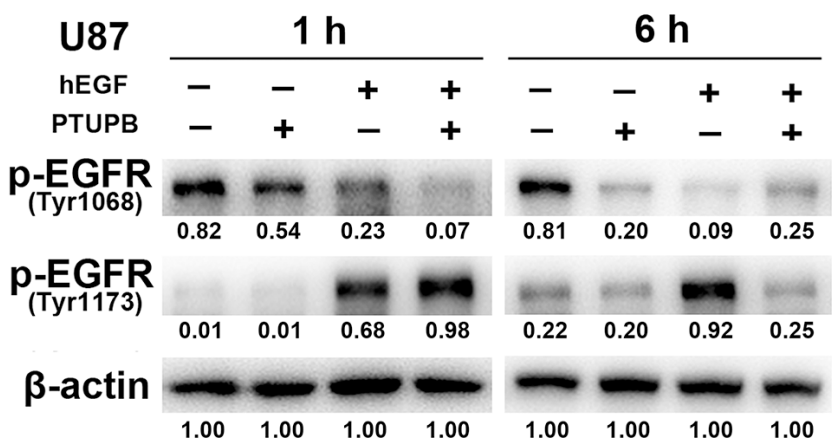

B

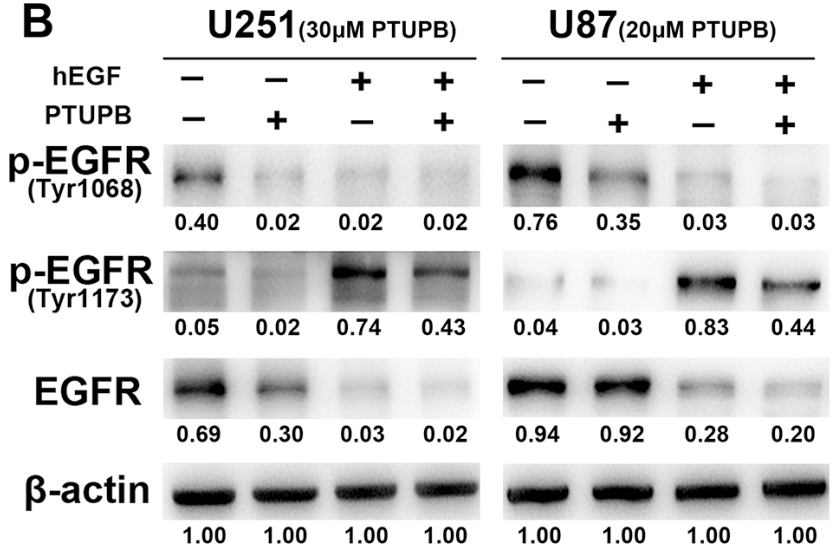

D

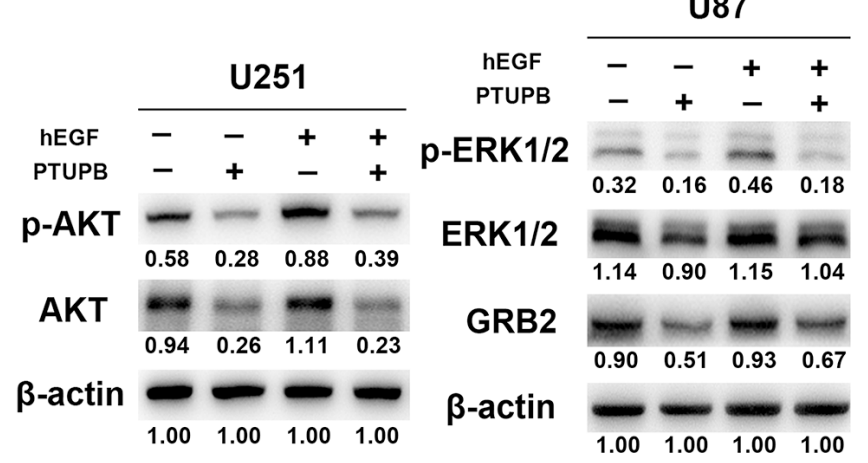

Figure 3: PTUPB targets EGFR signaling. (A) When cells were treated for $48 \mathrm{~h}$, a $30 \mu \mathrm{M}$ PTUPB concentration was needed to significantly reduce EGFR expression. When cells were treated with $30 \mu \mathrm{M}$ PTUPB, reduction in EGFR expression was seen until 24-h post treatment. (B) U251 cells were treated with $30 \mu \mathrm{M}$ PTUPB or/and $50 \mathrm{ng} / \mathrm{ml} \mathrm{hEGF}$ for $48 \mathrm{~h}$ and, U87 cells were treated with $20 \mu \mathrm{M}$ PTUPB or/and $50 \mathrm{ng} / \mathrm{ml} \mathrm{hEGF}$ for 48 h. $30 \mu \mathrm{M}$ PTUPB reduces expression of EGFR and depletes p-EGFR ${ }^{\text {Tyr1068 }}$ and p-EGFR ${ }^{\text {Tyr1 } 173}$. $20 \mu \mathrm{M}$ PTUPB also depletes p-EGFR ${ }^{\text {Tyr1068 }}$ and p-EGFR ${ }^{\text {Tyr1 } 173}$, but does not reduce EGFR protein expression. (C) In U87 cells, 1-h treatment of $30 \mu \mathrm{M}$ PTUPB depletes p-EGFR ${ }^{\text {Tyr1068 }}$ but not p-EGFR ${ }^{\text {Tyr1173; }}$; while 6-h treatment of $30 \mu \mathrm{M}$ PTUPB depletes p-EGFR ${ }^{\text {Tyr1 } 173}$ and p-EGFR ${ }^{\text {Tyr1068 }}$ (50 ng/ml hEGF was used as an EGFR activator). (D) U251 and U87 cells were treated with $30 \mu \mathrm{M}$ PTUPB in the presence or absence of $50 \mathrm{ng} / \mathrm{ml} \mathrm{hEGF}$ for $48 \mathrm{~h}$. PTUPB reduces the expression and phosphorylation of AKT and ERK1/2 and, the expression of GRB2. $\beta$-actin was used as a loading control. The immunoblotting bands were quantified by ImageJ and represented by relative values compare with loading control (1.00). 
also affects centrosome structure and regulates mitotic spindle formation [45, 46]. HMMR maintains the stemness and tumorigenicity of stem-like cells, which is essential for promoting tumorigenesis and angiogenesis in glioblastoma. Targeting HMMR has been demonstrated to inhibit the expression of stemness markers and regulators and the activation of ERK1/2 [22]. In the present study, we demonstrated that PTUPB also inhibits the expression of stemness maerkers BMI1, SOX2 and the activation of ERK1/2 in glioblastoma cell lines. Moreover, we found that the ZEB1 protein, a member of the ZEB family of zinc finger transcription factors, was dramatically suppressed by PTUPB. Very recently, ZEB1 has been identified as a potential SOX2 target, which is co-expressed with SOX2 in glioblastoma [23]. Our findings indicated that PTUPB may target the HMMR/SOX2/ZEB1 signaling axis, inhibiting glioblastoma growth.

In conclusions, we found that the $\mathrm{COX}-2 / \mathrm{sEH}$ dual inhibitor PTUPB suppresses human glioblastoma
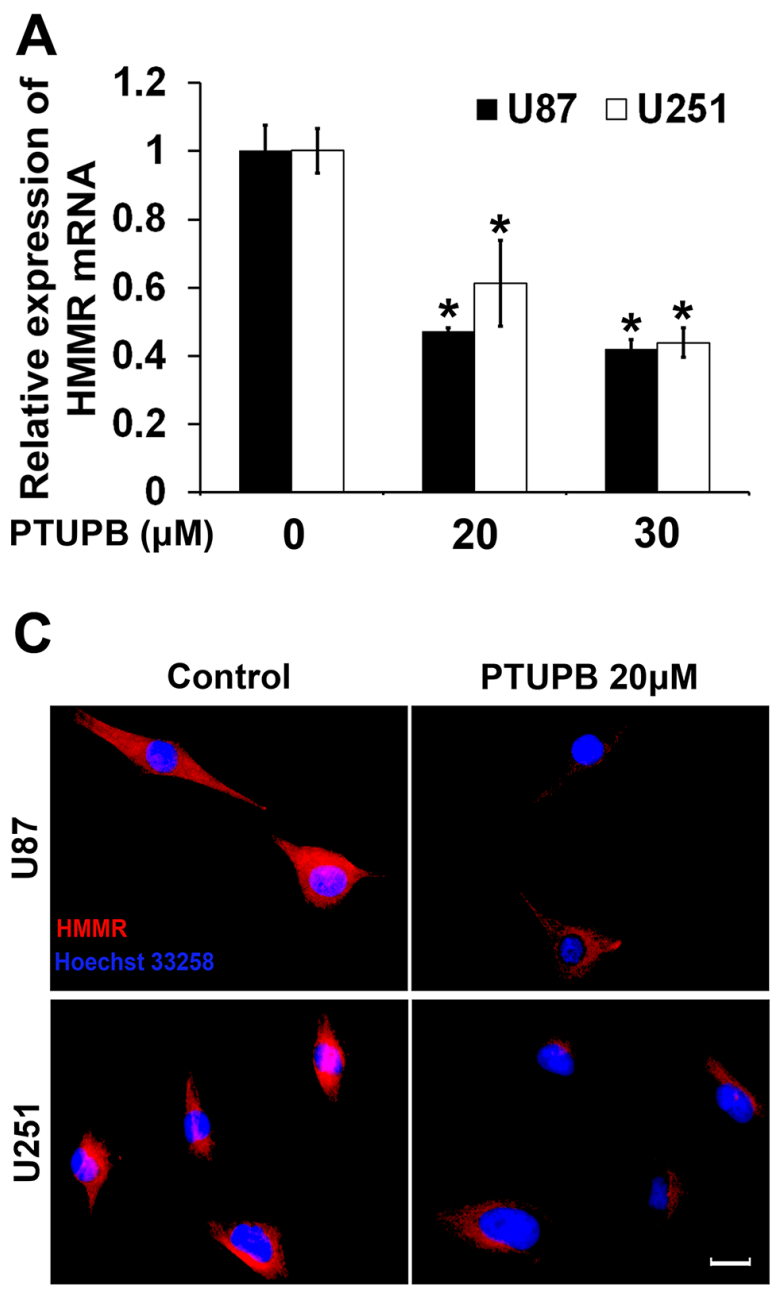

growth in vitro and in vivo, and dramatically inhibits EGFR signaling pathway and expression of HMMR and stemness markers and regulators. Therefore, PTUPB may be a potential therapeutic agent to treat glioblastomas.

\section{MATERIALS AND METHODS}

\section{Reagents}

The cyclooxygenase (COX)-2/soluble epoxide hydrolase (sEH) dual inhibitor, PTUPB, was synthesized by Dr. Sung Hee Hwang as described [18, 47]. The recombinant human EGF (hEGF) (\#8916) and primary antibodies against $\beta$-actin (\#3700), CDK2 (\#2546), p27 ${ }^{\text {Kip1 }}$ (\#3686), Cyclin D3 (\#2936), c-Myc (\#13987), Cyclin D1 (\#2978), p21 Waf1/Cip1 (\#2947), CDK4 (\#12790), CDK6 (\#3136), EGFR (\#4267), p-EGFR ${ }^{\text {Tyr1068 }}$ (\#3777), p-EGFR $^{\text {Tyr1173 }} \quad(\# 4407), \quad$ AKT $\quad(\# 2920), \quad$ p-AKT ${ }^{\text {Ser473 }}$

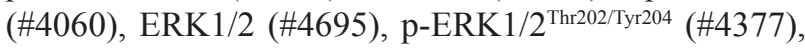

B

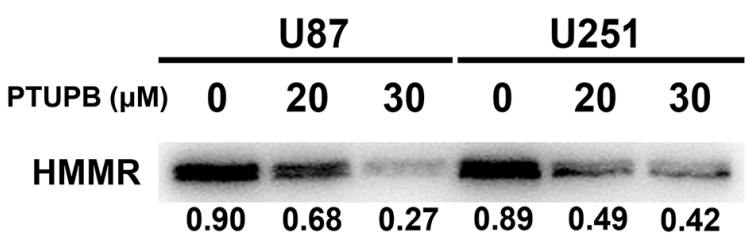

$\beta$-actin

$\begin{array}{lllll}0.68 & 0.27 & 0.89 & 0.49 & 0.42\end{array}$

D

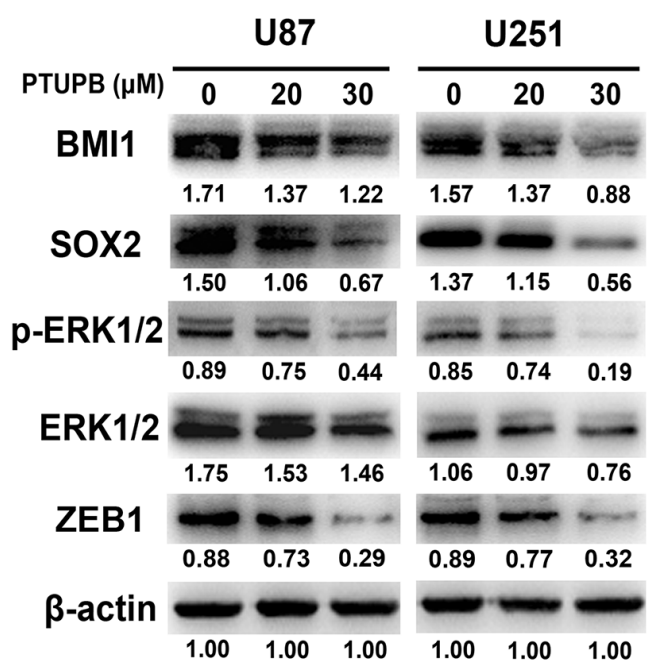

Figure 4: PTUPB suppresses expression of HMMR and stemness markers and regulators. (A) Quantitative real time-PCR assay showed that HMMR mRNA level is reduced by PTUPB $\left({ }^{*} P<0.05\right)$. The western blot assay (B) or cellular immunofluorescence (C) Scale bar $=10 \mu \mathrm{m}$ ) showed that HMMR protein level is significantly reduced by PTUPB. (D) The western blot assay showed that PTUPB suppresses the expression of BMI, SOX2 and ZEB1 and the activation of ERK1/2. $\beta$-actin was used as a loading control. The immunoblotting bands were quantified by ImageJ and represented by relative values compare with loading control (1.00). 
GRB2 (\#3972), BMI1 (\#6964), ZEB1 (\#3396) and SOX2 (\#3579) were all purchased from Cell Signaling Technology (Beverly, MA, USA). Antibody against HMMR (\#GTX121502) was purchased from GeneTex (Irvine, CA, USA).

\section{Cell culture}

Human glioblastoma cell lines U251 and U87 were purchased from CBTCCCAS (Cell Bank, Type Culture Collection of Chinese Academy of Sciences). All cells were cultured at $37^{\circ} \mathrm{C}$ in a humidified atmosphere of $95 \%$ air and $5 \% \mathrm{CO}_{2}$ by using the complete culture medium, Dulbecco's Modified Eagle's Medium (DMEM) supplemented with $10 \%$ fetal bovine serum (FBS) and 1\% penicillin and streptomycin.

\section{Cellular immunofluorescence assays}

Cells were transplanted into 6-well plates covered with circular coverslips in the bottom and allowed to attach overnight. After different treatment of PTUPB for $48 \mathrm{~h}$, cells were fixed by $4 \%$ paraformaldehyde. For phalloidin staining of actin fibers, fixed cells were incubated with fluorescein isothiocyanate (FITC)labeled phalloidin (Beyotime Institute of Biotechnology, Shanghai, China) for $60 \mathrm{~min}$ at room temperature and then mounted onto slides for observation after nuclei staining. For HMMR staining, fixed cells were probed with HMMR primary antibody (OriGene, Rockville, MD, USA) at $4^{\circ} \mathrm{C}$ overnight followed by incubation with Alexa Fluor 555-labeled secondary antibody (Beyotime Institute of Biotechnology, Shanghai, China) for $60 \mathrm{~min}$ at room temperature. Hoechst 33258 was used for staining nuclei. Cell samples were observed and pictures were taken by using a Zeiss Axio Scope.A1 microscope (Carl Zeiss, Oberkochen, Germany).

\section{Cell proliferation assay}

CCK-8 kit purchased from Dojindo Laboratories (Kumamoto, Japan) was used for cell proliferation assay. Cells were transplanted into 96-well plates followed by different treatment. After $72 \mathrm{~h}$, culture medium was discarded; cells were then cultured in $100 \mu \mathrm{l}$ fresh serumfree medium contained $10 \mu \mathrm{l}$ CCK-8 solutions for $2 \mathrm{~h}$. Then, the 96-well plate was put into an enzyme-linked immunosorbent assay plate reader (Bio-Rad Laboratories,
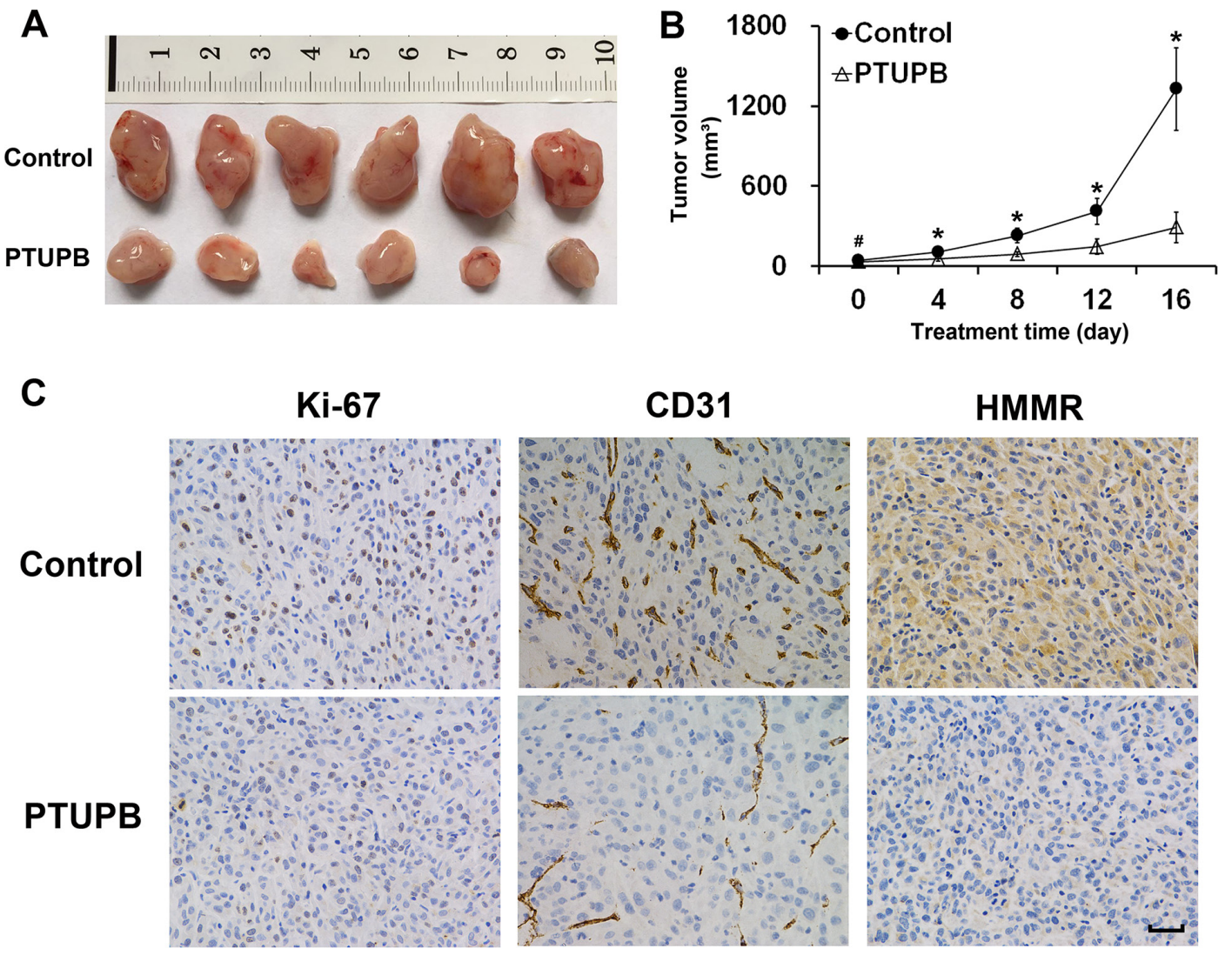

Figure 5: PTUPB suppresses glioblastoma growth in vivo. (A) Xenograft tumors were obtained from mouse models $(n=6$ mice per group). (B) Tumor bearing mice were treated with either vehicle control (1:1 (v/v) PEG 400/DMSO) or PTUPB (60 mg $\mathrm{kg}^{-1}$ $\mathrm{d}^{-1}$, dissolved in 1:1 (v/v) PEG 400/DMSO), and the tumor volumes were measured $\left({ }^{\sharp} P>0.05,{ }^{*} P<0.05\right)$. (C) The immunohistochemical staining shows that PTUPB suppresses expression of Ki-67, CD31 and HMMR in xenograft tumors. Ki-67 is positively stained in nuclei and, HMMR is generally stained in cytoplasm. CD31 is positively stained in vascular endothelial cell. Scale bar $=50 \mu \mathrm{m}$. 
Inc., Berkeley, CA, USA) and optical density values (absorbance) were recorded at $450 \mathrm{~nm}$. The relative cell survival rate was calculated according to the absorbance.

\section{Cell cycle analysis by flow cytometry}

As we described previously [48], the cell cycle analysis was performed using a FACS Calibur flow cytometer (BD Biosciences, San Jose, CA, USA). Briefly, cells were treated with either $20 \mu \mathrm{M}$ PTUPB or DMSO and harvested by trypsinization, centrifuged ( $3500 \mathrm{rpm}$ for $5 \mathrm{~min}$ ), and washed twice with PBS. Cells were then fixed by $75 \%$ ethanol. After staining using propidium iodide (PI), a total of 10,000 nuclei were analyzed.

\section{Quantitative real-time PCR assay}

Total RNA was extracted from cells samples by Trizol (Invitrogen) according to the manufacturer's instruction. Then, the RNA was reverse transcribed to form cDNA by SuperScript III Reverse Transcriptase (Invitrogen). ABI 7300 real-time PCR system (Applied Biosystems) was applied to perform real-time PCR using Fast Start Universal SYBR Green Master (Roche). The primers were: HMMR (Forward: CATGGTGCAGC TCAGGAACA; Reverse: AAGCTGACAGCGGAGTTT TG); $\beta$-actin (Forward: CACCCAGCACAATGAAGATCA AGAT; Reverse: CCAGTTTTTAAATCCTGAGTCAA GC). For data analysis, the $\Delta \Delta \mathrm{Ct}$ (comparative threshold cycle) method was used. The fold-change was calculated as $2^{-\Delta \Delta C t}$. The average expression of housekeeping genes ( $\beta$-actin) was used to normalize the data.

\section{Western blot analysis}

As we described previously [48], the whole cell lysates were prepared and separated by SDS-polyacrylamide gel electrophoresis (SDS-PAGE) and transferred to a polyvinylidene fluoride membrane (Millipore Corporation, Bedford, MA, USA). Membranes were incubated with primary antibodies at $4{ }^{\circ} \mathrm{C}$ overnight followed by incubation with secondary antibody. Immunoblots of proteins were visualized with chemiluminescence luminol reagents (Beyotime Institute of Biotechnology, Shanghai, China). Public software ImageJ (National Institutes of Health, USA) was used to quantify the densitometry of the immunoblotting bands.

\section{Tumor xenograft mouse model}

Animal experiments protocols were approved by Jinling Hospital animal studies committee. Approximately $5.0 \times 10^{6} \mathrm{U} 87$ cells were transplanted subcutaneously to BALB/c nude mouse (male at 5 to 6 weeks old) to develop a mouse xenograft model of human glioblastoma. Once tumor was palpable, the treatment of PTUPB
(60 $\mathrm{mg} \cdot \mathrm{kg}^{-1} \cdot \mathrm{d}^{-1}$, dissolved in a mixed solvent of PEG400 and DMSO, 1:1 vol/vol) or vehicle control (PEG-400 and DMSO, 1:1 vol/vol) was administered once daily by intraperitoneal injection. The length and width of the tumors were measured every other day using a vernier caliper, and the tumor volume was calculated (tumor volume $=1 / 2 \times$ length $\times$ width $^{2}$ ). 16 days after the treatment, all tumors obtained from animals were submitted for immunohistochemical staining to analyze the expression of Ki-67, CD31 and HMMR.

\section{Immunohistochemical staining}

Xenograft tumor tissues were obtained, paraffinembedded and tissue sections prepared. Briefly, specimen was cut as $4 \mu \mathrm{m}$-thick sections, which were then deparaffinized. $3 \% \mathrm{H}_{2} \mathrm{O}_{2}$ was used to quench endogenous peroxidase activity. Nonspecific bindings were blocked by normal goat serum. Immunostaining was performed using primary antibodies at either 1:100 or 1:200 dilution followed by incubation with HRP-labeled secondary antibody. The visualization signal was developed with 3,3'-diaminobenzidine (DAB), and then mounted. Tissue sections were observed and pictures were taken by using a Zeiss Axio Scope.A1 microscope (Carl Zeiss, Oberkochen, Germany).

\section{Statistical analysis}

The SPSS 17.0 software and Microsoft Excel were used for statistical analysis. Comparisons between treated and control groups were carried out using one-way ANOVA or independent $t$-test, and expressed as mean \pm standard deviation (SD). $P<0.05$ were considered statistically significant.

\section{Abbreviations}

CNS: central nervous system; COX-2: cyclooxygenase-2; ARA: arachidonic acid; PGE2: prostaglandin E2; EETs: epoxyeicosatrienoic acids; sEHIs: soluble epoxide hydrolase inhibitors; DHETs: dihydroxyeicosatrienoic acids; HMMR: hyaluronan mediated motility receptor; EGFR: epidermal growth factor receptor; DMSO: dimethyl sulfoxide; DMEM: Dulbecco's Modified Eagle's Medium; FBS: fetal bovine serum; CCK-8: cell counting kit-8; FITC: fluorescein isothiocyanate; PI: propidium iodide.

\section{Author contributions}

J.L., Y.Z., and H.W. designed the research; J.L., Y.Z., Y.G., L.L. and X.J. performed the research; S.H.H. and B.D.H. contributed reagents; J.L., Y.Z., and Y.G. analyzed the data; and J.L., S.H.H. and B.D.H. wrote the paper. 


\section{CONFLICTS OF INTEREST}

B.D.H. and S.H.H are authors of University of California patents on the synthesis and use of PTUPB. The other authors declare that they have no competing of interests.

\section{FUNDING}

This study was supported by National Natural Science Foundation of China 81301905 (to J.L.) and 81371357 (to H.W.); by Natural Science Foundation of Jiangsu Province BK20140731 (to X.J.); by NIEHS/R01 ES002710 (to B.D.H.); and by NIDDK R01 DK103616 (to B.D.H.).

\section{REFERENCES}

1. Chinot OL, Wick W, Mason W, Henriksson R, Saran F, Nishikawa R, Carpentier AF, Hoang-Xuan K, Kavan P, Cernea D, Brandes AA, Hilton M, Abrey L, et al. Bevacizumab plus radiotherapy-temozolomide for newly diagnosed glioblastoma. N Engl J Med. 2014; 370:709-722.

2. Wick W, Chinot OL, Bendszus M, Mason W, Henriksson R, Saran F, Nishikawa R, Revil C, Kerloeguen Y, Cloughesy T. Evaluation of pseudoprogression rates and tumor progression patterns in a phase III trial of bevacizumab plus radiotherapy/temozolomide for newly diagnosed glioblastoma. Neuro Oncol. 2016; 18:1434-1441.

3. Eckel-Passow JE, Lachance DH, Molinaro AM, Walsh KM, Decker PA, Sicotte H, Pekmezci M, Rice T, Kosel ML, Smirnov IV, Sarkar G, Caron AA, Kollmeyer TM, et al. Glioma Groups Based on 1p/19q, IDH, and TERT Promoter Mutations in Tumors. N Engl J Med. 2015; 372:2499-2508.

4. Chi AS, Sorensen AG, Jain RK, Batchelor TT. Angiogenesis as a therapeutic target in malignant gliomas. Oncologist. 2009; 14:621-636.

5. Chinot OL, Nishikawa R, Mason W, Henriksson R, Saran F, Cloughesy T, Garcia J, Revil C, Abrey L, Wick W. Upfront bevacizumab may extend survival for glioblastoma patients who do not receive second-line therapy: an exploratory analysis of AVAglio. Neuro Oncol. 2016; 18:1313-1318.

6. Nakamura K, Smyth MJ. Targeting cancer-related inflammation in the era of immunotherapy. Immunol Cell Biol. 2017; 95:325-332.

7. Ma X, Aoki T, Tsuruyama T, Narumiya S. Definition of Prostaglandin E2-EP2 Signals in the Colon Tumor Microenvironment That Amplify Inflammation and Tumor Growth. Cancer Res. 2015; 75:2822-2832.

8. Cheah MT, Chen JY, Sahoo D, Contreras-Trujillo H, Volkmer AK, Scheeren FA, Volkmer JP, Weissman IL. CD14-expressing cancer cells establish the inflammatory and proliferative tumor microenvironment in bladder cancer. Proc Natl Acad Sci U S A. 2015; 112:4725-4730.
9. Philip B, Roland CL, Daniluk J, Liu Y, Chatterjee D, Gomez SB, Ji B, Huang H, Wang H, Fleming JB, Logsdon CD, Cruz-Monserrate Z. A high-fat diet activates oncogenic Kras and COX2 to induce development of pancreatic ductal adenocarcinoma in mice. Gastroenterology. 2013; 145:1449-1458.

10. Fujita M, Kohanbash G, Fellows-Mayle W, Hamilton RL, Komohara Y, Decker SA, Ohlfest JR, Okada H. COX-2 blockade suppresses gliomagenesis by inhibiting myeloidderived suppressor cells. Cancer Res. 2011; 71:2664-2674.

11. Booth L, Roberts JL, Cruickshanks N, Tavallai S, Webb T, Samuel P, Conley A, Binion B, Young HF, Poklepovic A, Spiegel S, Dent P. PDE5 inhibitors enhance celecoxib killing in multiple tumor types. J Cell Physiol. 2015; 230:1115-1127.

12. Qian X, Gu L, Ning H, Zhang Y, Hsueh EC, Fu M, Hu X, Wei L, Hoft DF, Liu J. Increased Th17 cells in the tumor microenvironment is mediated by IL-23 via tumor-secreted prostaglandin E2. J Immunol. 2013; 190:5894-5902.

13. Kim HB, Kim M, Park YS, Park I, Kim T, Yang SY, Cho CJ, Hwang D, Jung JH, Markowitz SD, Hwang SW, Yang SK, Lim DS, et al. Prostaglandin E2 Activates YAP and a Positive-signaling Loop to Promote Colon Regeneration Following Colitis but Also Carcinogenesis in Mice. Gastroenterology. 2017; 152:616-630.

14. Wang D, Dubois RN. Eicosanoids and cancer. Nat Rev Cancer. 2010; 10:181-193.

15. Zeldin DC. Epoxygenase pathways of arachidonic acid metabolism. J Biol Chem. 2001; 276:36059-36062.

16. Spector AA, Fang X, Snyder GD, Weintraub NL. Epoxyeicosatrienoic acids (EETs): metabolism and biochemical function. Prog Lipid Res. 2004; 43:55-90.

17. Imig JD, Hammock BD. Soluble epoxide hydrolase as a therapeutic target for cardiovascular diseases. Nat Rev Drug Discov. 2009; 8:794-805.

18. Zhang G, Panigrahy D, Hwang SH, Yang J, Mahakian LM, Wettersten HI, Liu JY, Wang Y, Ingham ES, Tam S, Kieran MW, Weiss RH, Ferrara KW, et al. Dual inhibition of cyclooxygenase-2 and soluble epoxide hydrolase synergistically suppresses primary tumor growth and metastasis. Proc Natl Acad Sci U S A. 2014; 111:11127-11132.

19. Lynch DK, Winata SC, Lyons RJ, Hughes WE, Lehrbach GM, Wasinger V, Corthals G, Cordwell S, Daly RJ. A Cortactin-CD2-associated protein (CD2AP) complex provides a novel link between epidermal growth factor receptor endocytosis and the actin cytoskeleton. J Biol Chem. 2003; 278:21805-21813.

20. Rodriguez-Berriguete G, Torrealba N, Fraile B, Paniagua R, Royuela M. Epidermal growth factor induces p38 MAPKdependent G0/G1-to-S transition in prostate cancer cells upon androgen deprivation conditions. Growth Factors. 2016; 34:5-10.

21. Wertheimer C, Liegl R, Kernt M, Docheva D, Kampik A, Eibl-Lindner KH. EGFR-blockade with erlotinib reduces 
EGF and TGF-beta2 expression and the actin-cytoskeleton which influences different aspects of cellular migration in lens epithelial cells. Curr Eye Res. 2014; 39:1000-1012.

22. Tilghman J, Wu H, Sang Y, Shi X, Guerrero-Cazares H, Quinones-Hinojosa A, Eberhart CG, Laterra J, Ying M. HMMR maintains the stemness and tumorigenicity of glioblastoma stem-like cells. Cancer Res. 2014; 74:3168-3179.

23. Singh DK, Kollipara RK, Vemireddy V, Yang XL, Sun Y, Regmi N, Klingler S, Hatanpaa KJ, Raisanen J, Cho SK, Sirasanagandla S, Nannepaga S, Piccirillo S, et al. Oncogenes Activate an Autonomous Transcriptional Regulatory Circuit That Drives Glioblastoma. Cell Rep. 2017; 18:961-976.

24. Dandekar DS, Lokeshwar BL. Inhibition of cyclooxygenase (COX)-2 expression by Tet-inducible COX-2 antisense cDNA in hormone-refractory prostate cancer significantly slows tumor growth and improves efficacy of chemotherapeutic drugs. Clin Cancer Res. 2004; 10:8037-8047.

25. Kishi K, Petersen S, Petersen C, Hunter N, Mason K, Masferrer JL, Tofilon PJ, Milas L. Preferential enhancement of tumor radioresponse by a cyclooxygenase-2 inhibitor. Cancer Res. 2000; 60:1326-1331.

26. Wu K, Fukuda K, Xing F, Zhang Y, Sharma S, Liu Y, Chan MD, Zhou X, Qasem SA, Pochampally R, Mo YY, Watabe $\mathrm{K}$. Roles of the cyclooxygenase 2 matrix metalloproteinase 1 pathway in brain metastasis of breast cancer. J Biol Chem. 2015; 290:9842-9854.

27. Liu JY, Li N, Yang J, Li N, Qiu H, Ai D, Chiamvimonvat $\mathrm{N}$, Zhu Y, Hammock BD. Metabolic profiling of murine plasma reveals an unexpected biomarker in rofecoxibmediated cardiovascular events. Proc Natl Acad Sci U S A. 2010; 107:17017-17022.

28. Goswami SK, Wan D, Yang J, Trindade da Silva CA, Morisseau C, Kodani SD, Yang GY, Inceoglu B, Hammock BD. Anti-Ulcer Efficacy of Soluble Epoxide Hydrolase Inhibitor TPPU on Diclofenac-Induced Intestinal Ulcers. J Pharmacol Exp Ther. 2016; 357:529-536.

29. Schmelzer KR, Inceoglu B, Kubala L, Kim IH, Jinks SL, Eiserich JP, Hammock BD. Enhancement of antinociception by coadministration of nonsteroidal anti-inflammatory drugs and soluble epoxide hydrolase inhibitors. Proc Natl Acad Sci U S A. 2006; 103:13646-13651.

30. Liu JY, Yang J, Inceoglu B, Qiu H, Ulu A, Hwang SH, Chiamvimonvat N, Hammock BD. Inhibition of soluble epoxide hydrolase enhances the anti-inflammatory effects of aspirin and 5-lipoxygenase activation protein inhibitor in a murine model. Biochem Pharmacol. 2010; 79:880-887.

31. Schmelzer KR, Kubala L, Newman JW, Kim IH, Eiserich JP, Hammock BD. Soluble epoxide hydrolase is a therapeutic target for acute inflammation. Proc Natl Acad Sci U S A. 2005; 102:9772-9777.

32. Udagawa T, Yuan J, Panigrahy D, Chang YH, Shah J, D'Amato RJ. Cytochalasin E, an epoxide containing Aspergillus-derived fungal metabolite, inhibits angiogenesis and tumor growth. J Pharmacol Exp Ther. 2000; 294:421-427.

33. Hu J, Muller KA, Furnari FB, Cavenee WK, VandenBerg SR, Gonias SL. Neutralizing the EGF receptor in glioblastoma cells stimulates cell migration by activating uPAR-initiated cell signaling. Oncogene. 2015; 34:4078-4088.

34. Reardon DA, Wen PY, Mellinghoff IK. Targeted molecular therapies against epidermal growth factor receptor: past experiences and challenges. Neuro Oncol. 2014; 16:viii7-13.

35. Roth $\mathrm{P}$, Weller M. Challenges to targeting epidermal growth factor receptor in glioblastoma: escape mechanisms and combinatorial treatment strategies. Neuro Oncol. 2014; 16:viii14-19.

36. Thorne AH, Zanca C, Furnari F. Epidermal growth factor receptor targeting and challenges in glioblastoma. Neuro Oncol. 2016; 18:914-918.

37. Tsuchihashi K, Okazaki S, Ohmura M, Ishikawa M, Sampetrean O, Onishi N, Wakimoto H, Yoshikawa M, Seishima R, Iwasaki Y, Morikawa T, Abe S, Takao A, et al. The EGF Receptor Promotes the Malignant Potential of Glioma by Regulating Amino Acid Transport System xc(-). Cancer Res. 2016; 76:2954-2963.

38. Pala A, Karpel-Massler G, Kast RE, Wirtz CR, Halatsch ME. Epidermal to Mesenchymal Transition and Failure of EGFR-Targeted Therapy in Glioblastoma. Cancers (Basel). 2012; 4:523-530.

39. Rojas M, Yao S, Lin YZ. Controlling epidermal growth factor (EGF)-stimulated Ras activation in intact cells by a cell-permeable peptide mimicking phosphorylated EGF receptor. J Biol Chem. 1996; 271:27456-27461.

40. Toole BP. Hyaluronan: from extracellular glue to pericellular cue. Nat Rev Cancer. 2004; 4:528-539.

41. Turley EA, Noble PW, Bourguignon LY. Signaling properties of hyaluronan receptors. J Biol Chem. 2002; 277:4589-4592.

42. Crainie M, Belch AR, Mant MJ, Pilarski LM. Overexpression of the receptor for hyaluronan-mediated motility (RHAMM) characterizes the malignant clone in multiple myeloma: identification of three distinct RHAMM variants. Blood. 1999; 93:1684-1696.

43. Wang C, Thor AD, Moore DH 2nd, Zhao Y, Kerschmann R, Stern R, Watson PH, Turley EA. The overexpression of RHAMM, a hyaluronan-binding protein that regulates ras signaling, correlates with overexpression of mitogenactivated protein kinase and is a significant parameter in breast cancer progression. Clin Cancer Res. 1998; 4:567-576.

44. Hall CL, Yang B, Yang X, Zhang S, Turley M, Samuel S, Lange LA, Wang C, Curpen GD, Savani RC, Greenberg AH, Turley EA. Overexpression of the hyaluronan receptor RHAMM is transforming and is also required for H-ras transformation. Cell. 1995; 82:19-26.

45. Hamilton SR, Fard SF, Paiwand FF, Tolg C, Veiseh M, Wang C, McCarthy JB, Bissell MJ, Koropatnick J, 
Turley EA. The hyaluronan receptors CD44 and Rhamm (CD168) form complexes with ERK1,2 that sustain high basal motility in breast cancer cells. J Biol Chem. 2007; 282:16667-16680.

46. Maxwell CA, Keats JJ, Crainie M, Sun X, Yen T, Shibuya E, Hendzel M, Chan G, Pilarski LM. RHAMM is a centrosomal protein that interacts with dynein and maintains spindle pole stability. Mol Biol Cell. 2003; 14:2262-2276.

47. Hwang SH, Wagner KM, Morisseau C, Liu JY, Dong H, Wecksler AT, Hammock BD. Synthesis and structure- activity relationship studies of urea-containing pyrazoles as dual inhibitors of cyclooxygenase- 2 and soluble epoxide hydrolase. J Med Chem. 2011; 54:3037-3050.

48. Li J, Tang C, Li L, Li R, Fan Y. Quercetin sensitizes glioblastoma to t-AUCB by dual inhibition of Hsp27 and COX-2 in vitro and in vivo. J Exp Clin Cancer Res. 2016; $35: 61$. 